\title{
Review on Effects of Interaction on Learners' Language Production
}

\author{
Xueping $\mathrm{Li}^{1,{ }^{*}}$ \\ ${ }^{1}$ School of Foreign Languages, Inner Mongolia University for the Nationalities, Tongliao, China \\ *Correspondence: School of Foreign Languages, Inner Mongolia University for the Nationalities, Tongliao, China. \\ Tel: 86-1-577-151-9966. E-mail: lxpfsu@163.com
}

Received: July 15, 2014

doi:10.5430/wjel.v4n3p38

\author{
Accepted: August 19, $2014 \quad$ Online Published: September 8, 2014 \\ URL: http://dx.doi.org/10.5430/wjel.v4n3p38
}

\begin{abstract}
This article first reviews and then evaluates the findings of research on Language production from the perspective of interaction. Meanwhile, the rich evidence that previous studies both in China and foreign countries have provided is summarized to show the overall effects of interaction on language output, the specific language development under interaction, as well as efficient grouping types by way of interaction. The major research trend on interaction is thus concluded. Moreover, some recommendations for future research in this field are brought forward according to the literature and the particular teaching and learning context in China.
\end{abstract}

Keywords: effect; interaction; language production

\section{Introduction}

Fluent oral language production, one of the final goals in ESL/EFL teaching and learning, is inclined to be influenced greatly by learning environment, ways of cognition and certain emotional factors, so it proves to be a great difficulty for learners to conquer (Liu, 2009). Interactional structure embedded in conversation has been one of the focuses aiming at solving this problem since 1980s. As mentioned in Gass (2003), focused negotiation work may lead learners' attentional resources to particular "discrepancies" between their interlanguage and the target language, representing a stage for language learning and development for oral competence. As for the greater attention paid to oral language development in terms of interaction by foreign scholars, the situation in China is not so optimistic. Oral English level is just a reference but not obligatory in the national entrance examination. Therefore, in most learners' viewpoint, to pass the English examinations does not deserve too much attention and efforts on oral English. Besides, in most circumstances learners are provided with few opportunities to practice oral English, so they feel anxious and nervous in expressing themselves in English, which directly inhibits their desire to actively participate in oral English practice. Meanwhile, teachers' beliefs on oral English development have also been affected while they emphasize the importance of four skills in English teaching (Li, 2012). Moreover, fewer contexts of situation for English use except the classroom, insufficient materials for English teaching and learning in the country are possible reasons that hinder learners' oral English development, which reduces the opportunities for deep research on English production. Fortunately communicative approach and task-based approach become more and more popular in China, so different types of English output as well as those situations that promote language production can serve as optimal conditions for in-depth research. Therefore, in this review article, the most recent work on interaction and language output done by foreign scholars is summarized, as well as a look at what we have achieved in this field in China, with an aim to arise attention on the importance of interaction and language production in language learning, and provide some implications for further research, thus figuring out appropriate approaches applied in promoting oral language competence for language learners in China.

\section{Review and Evaluation on Relevant Researches}

\subsection{The Overall Effects of Interaction}

Recent studies have shown apparent evidence on the overall positive effects of interaction on L2 production. In their empirical study on the effect of interaction on nonnative speakers' production, Gass and Varonis (1994) compared completing tasks with and without the opportunity for interaction. A thorough analysis of conversations between 16 
NN-NS dyads of university students (with NNS of different L1 backgrounds) showed that the greatest effect on the successful completion of the task was the NNS's opportunity for preceding interaction. The prior interaction posed a significant facilitating role to yield better subsequent L2 production, suggesting that interactions with opportunities for modifications trigger IL restructuring and enhance more target-like production, but it seems that interaction didn't lead to better comprehension of NNSs by NSs. In addition, Swain \& Lapkin (1998) conducted a study focusing on why interaction in collaborative tasks promotes L2 learning, reflecting a real classroom setting with task-based approach. Grade 8 French immersion students were engaged in a jigsaw task, and data from one pair's dialogue was analyzed for the research questions. The result of the study confirmed the consideration: dialogue as an enactment of mental processes and occasions for L2 learning, reinforcing the important position that interaction stands in facilitating language development. Interestingly, in the study the students were allowed to use their L1 and L2 as tools to aid in solving some problems they encountered in the task, while in Chinese context, in most classrooms especially oral lessons teachers prefer not to allow learners to use their L1 but encourage them to use the target language to solve problems for exploring potential language development. Maybe it can be inferred from their study about how to appropriately draw the balance between learners' L1 and L2 in language learning in the learning environment of China. Besides, the data analyzed came from two learners of high proficiency level, so the authors claimed for further detailed analysis of data from different proficiency levels (e.g. two low-proficiency learners) in order to get more about the learners' performance, which will provide more convincing evidence for teachers to implement task-based interaction based on effective grouping. More evidence can also be found in what Mackey (1999) did in her study: a positive relationship between conversational interaction and language output has been confirmed. The learners who actively engaged themselves in the interaction had language output with more developmentally advanced structures than those who less actively engaged.

\subsection{Effects of Interaction on Specific Language Development}

Braidi (1995) reviewed several interaction studies and concluded that those studies reveal the nature of NS-NNS/NNS-NNS interaction, but they do not reveal the effect of interactions on grammatical development, nor do they consider the relationship between interactional structure and grammatical structure. So he claimed a necessary step to remedy the situation by examining the interaction from a more detailed grammatical perspective. An approach to study L2 interaction that centers on the L2 grammatical development was proposed by Braidi (1995). He focused on the characteristics of interaction that are relevant to grammatical development (within a UG framework), that are available and accessible to the learner, and that have effects on L2 grammatical development. He argued that interaction makes the input comprehensible to the learner, highlighting the required input for the learner. Though not all the learners will necessarily take up the input, the interactional structure of the input will make some language aspects such as structures or language points more salient or accessible to the learner somehow. He emphasized that interactional modifications are helpful to L2 learners since they monitor comprehensibility, and the linguistic form is available to the learner in the interaction as a kind of input, with which the learner has accessibility to get selective attention to form. By focusing on grammar with the above criteria (relevance, availability, accessibility and effect), he proposed that detailed information about the structural characteristics of interaction that are relevant to the acquisition of specific grammatical structures can be provided, thus reinforcing the facilitating effect of interaction on language development for the benefit of the learner. He put forward a broader view to have a closer look at the effect of interaction on language development, and has brought out many recommendations for further study on interaction such as whether the structure of negotiated interaction enhances the accessibility of particular structures for the learner.

In addition, Kawaguchi and Ma's (2012) study also attempted to probe into the effect of interaction on learners' grammatical development. More comprehensive than other studies, this study began with the task-based interaction between traditional native-nonnative interaction (native English speakers and second language learners), as well as interaction between second language learners (with one group of same proficiency level and the other different). Corrective feedback and negotiation of meaning were taken into consideration. The study confirmed the positive effect of nonnative learners' interaction with low-high proficiency for the grammar development as a result of different successful meaningful negotiation of meaning and uptake of corrective feedback. And it further revealed that traditional native-nonnative interaction may be beneficial for pronunciation and vocabulary acquisition rather than grammar learning. But in-depth analysis remained inadequate on how much uptake of corrective feedback triggered in the interaction was obtained and what were possible corresponding factors that may affect the uptake.

Additional research also adopted the way Braidi (1995) did and focused on specific effects of interaction on L2 production. For example, empirical support from Mackey and Philp's (1998) study indicated the positive effects of recasts generated in the interaction on the acquisition of certain syntactic structures by adult L2 learners. The study 
investigated the effects of negotiated interaction on the production and development of question forms in an ESL context. Two of interactional features "recast" and the learners' immediate response are the focus of the study. The relationship between recasts in conversational interaction and short-term second language development was explored by comparing groups of learners who received interactionally modified input with learners who received the same input containing intensive recasts. 35 adult ESL learners from beginner and lower intermediate intensive English language classes in Sydney participated in the study, and completed "spot the difference" task and story completion task. They aged from 15-30 and were of mixed L1 backgrounds. The NSs were the two researchers and three project research assistants. The result of the study reinforced the positive effect of interaction on learners' output through the provision of extensive recasts within the interaction. On the other hand, the study suggested that recasts may be used evenly by some learners, but no reason that why some but not all the learners used recasts, nor explanation on the factors that may influence their decisions has been provided in the study. In addition, the study just showed the short-term effect of recasts triggered in interaction, longitudinal study on the long-term effect of interaction on language output is needed in the future research. From the similar perspective, Philp's (2003) study investigated the extent to which learners may notice native speakers' reformulations of their IL grammar in the context of dyadic task-based interaction. NS-NNS pairs were formed for the 33 (17-30 years of age and various L1 backgrounds) adult ESL learners to work on oral communication tasks. Results indicated that learners noticed over $60-70 \%$ of recasts, but there was no further analysis on possible reasons of noticing and non-noticing of the recasts, nor did we know the benefits of those noticing on subsequent oral language development.

From the similar perspective, some research has also highlighted the retention that "pushed output" by interaction may have on learners' language development. Nobuyoshi and Ellis (1993) conducted a small-scale pilot study. Each learner (six participants) performed with the researcher in two-way information tasks. The three experimental participants experienced "focused meaning negotiation", in which the researcher posed a clarification request when an utterance with a past tense error occurred in the participant's utterance; while the other three control participants experienced "unfocused meaning negotiation" (i.e. negotiation took place when a genuine communication problem arose). One week later, the repeated information-gap task (this time without a special focus on past tense) with the two groups of participants showed that two of the three experimental participants improved past tense use as a result of the clarification request and maintained the improvement one week later. Their findings made it clear that pushed output by way of interaction may get learners to gain more control over target language structures that they've already acquired, and it will bring in a long-term effect if learners are pushed to produce more comprehensible output, but not necessarily for all learners. That means that several factors are worthy to be explored in affecting language production in the interaction process.

\subsection{Effects of Interaction in Terms of Grouping Type}

The studies mentioned previously are focusing on the interaction between language learners. In comparison, Musumeci (1996) probed into the effects of interaction in teacher-learner negotiation. The study had a look at teacher-student exchanges in three content-based language classrooms. The results showed that in the three classes, the three participating native Italian teachers dominated the class and spoke most of the time. Teacher-initiated message exchanges exceeded student-initiated ones and more surprisingly, negotiation that led to modified output for language learners did not occur in this content-based setting, which does not echo those findings in which interaction has positive effects on learners' language output. As Musumeci (1996) has mentioned, several factors played crucial roles in the final result: such as the small sample size of teachers (three teachers in the study), affective variables in L2 learning, power relations between teachers and learners, and so on. In other words, how to feasibly promote more interacted negotiation in the task-based activities still poses challenges for teachers.

By comparing peer-peer and teacher-pupil interactions, Van den Branden (1997) conducted a quasi-experimental study with an aim to investigate the effects of types of negotiation on learners' output. The participants in the study were three groups of 16 child learners of Dutch (NS and NNS). They were asked to participate in a communicative activity: to orally describe a series of pictures to a partner. On the whole, the results indicated that the type of feedback the participants received in the interaction (both peer interaction and teacher-pupil interaction) resulted in modified output; negotiations triggered during the interaction had significant delayed effects on the learners' output: in a post-test with the same communicative task, the language learners who had experienced the preceding process of negotiations with pushed output, produced a greater quantity of output with a greater range of vocabulary and more essential information, but with no significant improvement in syntactic complexity or grammatical correctness. Most importantly, the researcher found that compared with teacher-learner interaction, the learners in peer interaction paid much more attention to organization of negotiation of content to complete the task, while in teacher-pupil interaction the pupil benefited a lot from the opportunity that generated interactional modified output for language learning. And 
negotiation of form only occurred in the teacher-pupil interaction. The study has provided a clear indication of the potential effects of negotiation on language acquisition, but with no measure of it. Besides, the study provided no empirical evidence for the effects of negotiation on subsequent language output.

The similar result was gained in Han Qin, et al. (2013)' study with 188 students in a 16 weeks' thinking intervention program: in group member construction, members of different proficiency levels may play a significant role in learning; moreover, from the perspective of task level interference, the study showed that task difficulty had less effect on the peer-interaction. Significantly, the new finding was that higher peer-interaction ability proved to enhance learners' higher creative problem-finding ability, which leaves much room for further research on relationship between interaction and learners' cognitive process in language learning.

\subsection{Summary}

As is shown in the above studies, the major trend of the studies concerning interaction is from the overall effects of interaction (Gass \&Varonis, 1994; Mackey, 1999; Li, 2012; Bagheri et al, 2012; etc) to some specific language development such as grammatical development (Braidi, 1995), recasts (Philp, 2003), task types and grouping in interaction (Kawaguchi \& Ma, 2012). Participants were among college students, with only a few with middle school students $(\mathrm{Hu}, 2012)$. In general, these above findings mainly were obtained in communicative tasks and oral language output has gained much emphasis. From quite different perspective, a few researchers have expanded their vision and paid attention to other forms of language output. Baleghizadeh (2010) examined the impact of peer interaction on an editing activity, focusing on written language output; and Behjat (2011) testified the feasibility of interaction in reading activities and focused on reading comprehension ability under interaction, which offers more evidence as well as perspectives in researching effects of interaction on language output.

In summary, researches focusing on interaction in ESL/EFL environment adopted similar methods: classroom settings with task-based approach, involving two major grouping types (learner-learner interaction and learner-teacher interaction), as well as comparison among group members of different proficiency levels. Moreover, the following issues have been covered: the overall positive effects of interaction on language output, the existence of interactional modifications in NS-NNS/NNS-NNS interactions, the discourse features that affect the subsequent occurrence of interactional modifications, as well as the relation between different types of interaction and L2 development. As is shown in the above studies, more issues, such as the cognitive process of learners in the interaction, affective variables of both teachers and learners, longitudinal effect of interaction on language development both in oral and written output and so on, should gain emphasis in further research.

\section{Implications for the Trend of Further Research}

From the review we can see that a growing body of research have driven their focus on effect of interaction on language production and made great contribution to this field, but there are still areas less touched. With regard to what have been done in the literature, together with particular ESL/EFL learning and teaching situation in China, the following aspects can be taken as references in future research:

1) From a more general frame, teachers' and students' beliefs on interaction should gain priority in performing tasks since beliefs may be of the major effects affecting their action and decisions in learning environment;

2) More studies are needed to show both learners and teachers' perception on interaction in different learning stages. Being acquainted with the perception will guide appropriate adjustment of teaching approaches;

3) Learners' cognitive process in language learning is more complex and may affect their choice of learning strategies and learning outcome, therefore, it should be taken into consideration when they are involved in different situations of interaction;

4) Much attention is needed to focus on learners' uptake immediate after interaction and the long-term effect on their L2 language development;

5) Task types and grouping methods may be possible factors that affect interaction, which may lead to different effects of interaction on language production, so they need more empirical evidence;

6) In China, learners of minority nationalities such as Mongolian have special English learning experience, with Mongolian their mother tongue, Chinese second language and English a foreign one. Their language learning process proved to be more complicated and has much room for exploration with view to language production.

In fact, Vygostky emphasized that the effective learning results from interaction with people with different levels of 
skill and knowledge, and learners perform better with others in language learning than they can do without assistance (Shrum \& Glison, 2003), so with interaction gaining more and more attention in language learning and research, more empirical studies are needed to testify the effectiveness for ESL/EFL learners and explore efficient ways appropriate for enhancing oral competence development for learners in China.

\section{Acknowledgements}

This article is one of the achievements of the research projects sponsored by the Planned Project of Inner Mongolian Philosophy and Social Science (ID: 2013B132) and the Scientific Research Project of Inner Mongolia University for the Nationalities (ID: NMD1153).

\section{References}

Braidi, S. M. (1995). Reconsidering the Role of Interaction and Input in Second Language Acquisition. Language Learning, 45, 141-175. http://dx.doi.org/10.1111/j.1467-1770.1995.tb00965.x

Fatemeh Behjat. (2011). Reading through Interaction: From Individualistic Reading Comprehension to Collaborareading. Theory and Practice in Language Studies, 3, 239-244.

Gass, S., \& Varonis, E. (1994). Input, Interaction, and Second Language Production. Studies in Second Language Acquisition, 16, 283-302. http://dx.doi.org/10.1017/S0272263100013097

Gass, S. M. (2003). Input and Interaction. In Doughty C. J. \& Michael. H. Long (Eds.), The Handbook of Second Language Acquisition (pp. 224-255). London: Longman.

Liu Zhongzheng. (2009). On the Influential Factors for L2 Learners'Oral Language Production. Foreign Languages and Their Teaching, 7, 26-28.

Mackey, A., \& Philp, J. (1998). Conversational Interaction and Second Language Development: Recasts, Responses, $\begin{array}{lllll}\text { and Red Herrings? Modern } & \text { Language Journal, }\end{array}$ http://dx.doi.org/10.1111/j.1540-4781.1998.tb01211.x

Mackey, A. (1999). Input, Interaction and Second Language Development. Studies in Second Language Acquisition, 21, 557-587. http://dx.doi.org/10.1017/S0272263199004027

Mohammad Sadegh Bagheri, Forough Rahimi \& Mohammad Javad Riasati. (2012). Communicative Interaction in Language Learning:Tasks among EFL Learners. Journal of Language Teaching and Research, 5, 948-952.

Musumeci, D. (1996). Teacher-learner Negotiation in Content-based Instruction: Communication at Cross-purposes? Applied Linguistics, 17, 286-325.

Nobuyoshi, J., \& Ellis, R. (1993). Focused Communication Tasks and Second Language Acquisition. English Language Teaching Journal, 47, 203-210. http://dx.doi.org/10.1093/elt/47.3.203

Philp, J.(2003). Constraints on "Noticing the gap": Non-native Speakers' Noticing of Recasts in NS-NNS Interaction. Studies in Second Language Acquisition, 25, 99-26.

Qin Han, Weiping Hu, Jia Liu, Xiaojuan Jia \& Philip Adeyd. (2013). The Influence of Peer Interaction on Students' Creative Problem-Finding Ability. Creativity Research Journal, 25(3), 248-258. http://dx.doi.org/10.1080/10400419.2013.813754

Sasan Baleghizadeh. (2010). The Impact of Peer Interaction on an Editing Activity in EFL Classes. Journal of Language Teaching and Research, 5, 721-727.

Satomi Kawaguchi \& Yuan Ma. (2012). Corrective Feedback, Negotiation of Meaning and Grammar Development: Learner-Learner and Learner-Native Speaker Interaction in ESL. Open Journal of Modern Linguistics, 2, 57-70. http://dx.doi.org/10.4236/ojml.2012.22008

Shrum, Judith L., \& Glisan, Eileen W. (2003). Teacher's Handbook: Contextualized Language Instruction. Beijing: Foreign Language Teaching and Research Press.

Swain, M., \& Lapkin, S. (1998). Interaction and Second Language Learning: Two Adolescent French Immersion Students Working Together. The Modern Language Journal, 82(3), 337. http://dx.doi.org/10.1111/j.1540-4781.1998.tb01209.x

Van den Branden, K. (1997). Effects of Negotiation on Language Learners' output. Language Learning, 47(4), 
589-636.

Wang, Qiaoying, \& Carolyn D. Castro. (2010). Classroom Interaction and Language Output. English Language Teaching, 3, 175-186. http://dx.doi.org/10.5539/elt.v3n2p175

Wenhua Hu. (2012). Gendered EFL Classroom Interaction-A Case Study in a Senior Middle School in China. Theory and Practice in Language Studies, 9, 1818-1827.

Xuemei Meng. (2011). Action Study of Teacher's Language on EFL Classroom Interaction. Theory and Practice in Language Studies, 1, 98-104. http://dx.doi.org/10.4304/tpls.1.1.98-104

Xueping Li. (2012). Effects of Negotiated Interaction on Mongolian-nationality EFL Learners' Spoken Output. English Language Teaching, 6, 119-134. 